\title{
Application of Gaseous Laser Targets and Optica Diagnostics to Study High Mach Number Unstable Plasma Flows
}

\author{
M.J. Edwards, A. MacKinnon, H. Robey
}

April 2001

U.S. Department of Energy

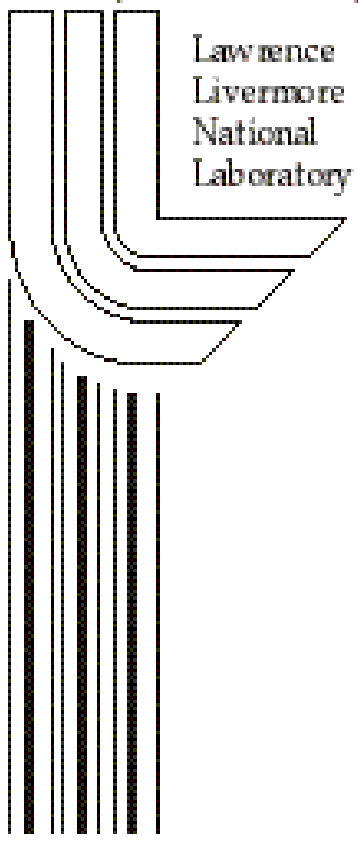




\section{DISCLAIMER}

This document was prepared as an account of work sponsored by an agency of the United States Government. Neither the United States Government nor the University of California nor any of their employees, makes any warranty, express or implied, or assumes any legal liability or responsibility for the accuracy, completeness, or usefulness of any information, apparatus, product, or process disclosed, or represents that its use would not infringe privately owned rights. Reference herein to any specific commercial product, process, or service by trade name, trademark, manufacturer, or otherwise, does not necessarily constitute or imply its endorsement, recommendation, or favoring by the United States Government or the University of California. The views and opinions of authors expressed herein do not necessarily state or reflect those of the United States Government or the University of California, and shall not be used for advertising or product endorsement purposes.

This work was performed under the auspices of the U. S. Department of Energy by the University of California, Lawrence Livermore National Laboratory under Contract No. W-7405-Eng-48.

This report has been reproduced directly from the best available copy.

Available electronically at http://www.doc.gov/bridge

Available for a processing fee to U.S. Department of Energy

And its contractors in paper from

U.S. Department of Energy

Office of Scientific and Technical Information

P.O. Box 62

Oak Ridge, TN 37831-0062

Telephone: (865) 576-8401

Facsimile: (865) 576-5728

E-mail: reports@adonis.osti.gov

Available for the sale to the public from

U.S. Department of Commerce

National Technical Information Service

5285 Port Royal Road

Springfield, VA 22161

Telephone: (800) 553-6847

Facsimile: (703) 605-6900

E-mail: orders@ntis.fedworld.gov

Online ordering: http://www.ntis.gov/ordering.htm

OR

Lawrence Livermore National Laboratory

Technical Information Department's Digital Library

http:/ / www.llnl.gov/tid/Library.html 


\title{
Application of gaseous laser targets and optical diagnostics
}

\author{
to study high Mach number unstable plasma flows
}

\section{Introduction}

\author{
J Edwards, A Mackinnon and H Robey
}

The information that can be obtained from current laser driven high Mach number (compressible) hydrodynamics experiments using solid targets and foams is limited by the need to use X-ray diagnostics. These do well at providing the shape of gross 2D structures which we model well, but are a long way from being able to reveal detailed information at the smaller spatial scales, or in 3D turbulent flows, where most of the modeling uncertainties exist ${ }^{1}$. Remedying this is, and will continue to be, an ongoing research effort. An alternative approach that is not being considered is to use gaseous targets coupled with optical diagnostics. The lower density of gases compared to solids or foams means we can use much larger targets for a given laser energy. This should significantly improve spatial resolution, and the dynamic range of scales that are resolvable. In addition, it may be possible to adapt powerful techniques, such as LIF, used by the low Mach number (incompressible) fluid/gas community so that they work in the high Mach number plasma regime. This would provide much more detailed information on turbulent flows than could be achieved with current X-ray diagnostics.

We propose a small research effort to use established techniques such as optical interferometry (absolute electron density), and Schlieren photography (electron density gradient), to study compressible hydrodynamic instabilities. We also propose to explore whether techniques such as LIF may be adapted to the plasma regime, thus providing detailed information, particularly about turbulent flows, that is not currently obtainable in plasmas using X-ray diagnostics. The setting will be radiating blast waves, which avoids costly target fabrication, while promising a high physics payoff to the astrophysics community just from using the established diagnostics alone. We propose to conduct the work in collaboration with Dr Todd Ditmire at the University of Texas at Austin, principally on the Janus laser, and Ditmire's short pulse laser, which is expected to be operational towards the beginning of FY02. Dr Stephen Rose at AWE has expressed interest in collaboration and would provide computational support. He would also look into using the Helen laser at AWE, and developing a UK university contact.

\section{Other potential for gaseous targets}

In addition to enabling the use of optical diagnostics, gases have additional attractions. It should be possible to pre-disturb the gas, allowing us to study new physics. Two scenarios are of particular interest: density gradients, and pre-turbulent flows. The former is expected to result in new manifestations of hydrodynamic instability as well as other phenomena, which would not occur in a flat density field. The latter is of interest because little is known about the interaction of turbulent flows with shock waves, or their equation of state.

On the other hand, gases clearly do not lend themselves to complicated, multi-component targets, without the use of relatively massive membranes, which often end up significantly disturbing the experiment. Nevertheless, techniques have been demonstrated for forming simple two-component membraneless targets. Therefore, even if complex targets cannot ultimately be made using gases, the simpler targets should still prove very valuable for the V\&V class of hydrodynamics experiments.

\section{Relevance to astrophysics community}

Casting the work under radiating blast waves not only allows complex, unstable flows to develop, but makes it relevant to the evolution of supernova remnants. Radiation cooling of the remnant has two important consequences[1,2,3]: the trajectory is slowed relative to an energy conserving Sedov-Taylor wave, which can affect the inferred age of the remnant; the pressure of the bast wave shell becomes inadequate for it to support itself against the incoming ram pressure of the surrounding interstellar medium, and the shell collapses to high density, making it very susceptible to thin shell instabilities

\footnotetext{
${ }^{1}$ An exception is some form of 2-color radiography or spectroscopy to obtain the distribution of two materials in a mix region, averaged along the diagnostic line of sight. This was partially successful on Nova and should be realized soon on Omega.
} 
such as Vishniac's overstability[4,5]. This can substantially affect the sphericity of the remnant, and the distribution of materials within it, both of which may influence our understanding of the explosion mechanism[2,6]. In practice, magnetic fields would limit the collapse of the shell, which would have a knock-on effect on the instability. Key elements of laboratory experiments should be well controlled conditions, and high resolution measurements to help validate computational tools[7].

\section{Previous work}

To date there have been surprisingly few experiments that have addressed the above topics. Grun et al. reported the growth of a Vishniac like instability in $\mathrm{cm}$ scale spherical blast waves in xenon gas on $\mathrm{a} \sim 100 \mathrm{~J}$ facility[8]. More recently Shigemori reported on weakly radiating $\sim \mathrm{mm}$ scale cylindrical blast waves produced in a gas jet using the $\sim 100 \mathrm{~mJ}$ Falcon laser at LLNL and optical interferometry[9]. Other experiments have been performed but have added little to the understanding gained in refs 8 and 9. Electron conduction effects modify the experiments in ref. 9, but this could be varied by introducing $\sim 1$ T static magnetic field.

\section{Proposed research}

Initial experimental work will focus on a simple blast wave environment, and have a high probability of success. The physics objective of the research would be to study the detailed behavior and stability of blast waves as radiative cooling becomes gradually more important. While spherical geometry is clearly the test bed of choice, cylindrical blast waves have some diagnostic advantages as well as exhibiting different growth rates for azimuthal and longitudinal modes which is of academic interest. Spherical blast waves will be created by illuminating thin foils in a low density background gas which fills the Janus target chamber. Cylindrical blast waves will be formed in a gas jet (as in ref [9]) at the Austin laser. As the test bed developed, and depending on progress, more ambitious experiments could be attempted. Eventually we would investigate the introduction of a gas jet/curtain or wire array into a background gas to provide an obstacle to promote mixing and turbulence.

In parallel, we would carry out design studies to explore the feasibility of adapting techniques such LIF for use in plasmas, and to examine the possible role of magnetic fields, both to modify the physical behavior, and as a potential diagnostic.

The order of priority of experiments would be:

1. optical interferometry and Schlieren photography to study blast wave stability

2. explore LIF type techiniques in plasmas

3. explore introduction of a static $\sim 1 \mathrm{~T}$ magnetic field to magnetize electrons and inhibit conduction

4. explore introduction of a gas jet/curtain in a background gas in the Janus chamber to act as an obstacle for the blast wave

This work was performed under the auspices of the U.S. Department of Energy by the University of California, Lawrence Livermore National Laboratory under Contract No. W-7405-Eng-48.

\section{References}

1. $\quad$ C. F. McKee and B. T. Draine, Science 252, 397 (1991).

2. J. M. Blondin, E. B. Wright, K. J. Borkowski, and S. P. Reynolds, Ap. J. 500, 342 (1998).

3. D. F. Cioffi, C. F. Mckee, and E Bertshinger, Ap. J. 334, 252, (1988).

4. $\quad$ E. T. Vishniac, Ap. J. 274, 152 (1983).

5. $\quad$ D. D. Ryutov, M. S. Derzon, and M. K. Matzen, Rev. Mod. Phys. 167, 72 (2000).

6. A. M. Khokhlov et al, Ap. J. 524, L107, (1999).

7. D. Arnette, priv. comm. (2001).

8. J. Grun, J. Stamper, C. Manka, J. Resnick, R. Burris, J. Crawford, and B. H. Ripin, Phys. Rev. Lett. 66, 2738-2741 (1991).

9. $\quad$ K. Shigemori, et al., Ap. J. Lett. 533, L159 (2000). 